Etnográfica

Revista do Centro em Rede de Investigação em

Antropologia

vol. 25 (3) | 2021

Vol. 25 (3)

\title{
O trabalho de campo e suas perspectivas: encontros antropológicos entre pesquisadora e sacerdote no tambor de mina
}

Fieldwork and its perspectives: anthropological encounters between researcher and priest in Mina's Drum (Tambor de Mina)

\section{Marilande Martins Abreu}

\section{CpenEdition}

\section{Journals}

\section{Edição electrónica}

URL: https://journals.openedition.org/etnografica/10704

DOI: 10.4000/etnografica. 10704

ISSN: 2182-2891

\section{Editora}

Centro em Rede de Investigação em Antropologia

\section{Edição impressa}

Data de publição: 1 outubro 2021

Paginação: 611-631

ISSN: 0873-6561

Refêrencia eletrónica

Marilande Martins Abreu, «O trabalho de campo e suas perspectivas: encontros antropológicos entre pesquisadora e sacerdote no tambor de mina», Etnográfica [Online], vol. 25 (3) | 2021, posto online no dia 29 outubro 2021, consultado o 09 janeiro 2022. URL: http://journals.openedition.org/etnografica/ 10704 ; DOI: https://doi.org/10.4000/etnografica.10704

\section{(c) (†) 8}

Etnográfica is licensed under a Creative Commons Attribution-NonCommercial 4.0 International License. 


\section{O trabalho de campo e suas perspectivas: encontros antropológicos entre pesquisadora e sacerdote no tambor de mina}

\section{Marilande Martins Abreu}

O presente artigo se propõe refletir sobre o trabalho de campo e as relações entre a pesquisa na mina e o sacerdócio da mina. É fruto de dois textos sobre o tambor de mina do Maranhão escritos pela antropóloga Mundicarmo Rocha Ferretti e pelo pai-de-santo Euclides Pereira, um dos mais importantes líderes de cuidado e transmissão com as práticas de ancestralidade africana. Pretende-se compreender como esses dois escritos indicam formas do fazer antropológico que não se reduzem a troca de posições entre pesquisadora e sacerdote, mas dos diálogos que ambos, a partir de suas movimentações e posições, constroem nos textos, que ao invés de rivalizarem tornam-se expressões e experiências do tambor de mina possíveis de serem transformadas em escrita etnográfica do tambor de mina.

PALAVRAS-CHAVE: tambor de mina, campo intelectual, campo religioso.

Fieldwork and its perspectives: anthropological encounters between researcher and priest in Mina's Drum (Tambor de Mina) - The present article proposes to reflect on the fieldwork and the relations between the religious and afro-maranhense fields from two texts about the Maranhão Mine Drum (Tambor de Mina do Maranhão). It is intended to understand how these two writings indicate a possibility of changes of positions, in so far as the anthropologist's text can be interpreted from the religious discourse, and the Mina priest's text from the anthropological position.

KEYWORDS: mine drum, intellectual field, religious field, truth.

ABREU, Marilande Martins (marilande.ma@ufma.br) - Universidade Federal do Maranhão - UFMA, Departamento de Sociologia e Antropologia, Grupo de Pesquisa GP de Mina. 


\section{INTRODUÇÃO}

Este ensaio situa-se na análise das relações entre o campo religioso e o campo intelectual. ${ }^{1}$ É uma tentativa de apreender como os termos, os signos e símbolos circulam como linguagem uníssona na narrativa que liga o Benin ao Maranhão, a Casa das Minas de São Luís/MA, aos Voduns do antigo Daomé. Ou ainda, os elos entre os escritos de pai Euclides da Casa Fanti-Ashanti, e da antropóloga Mundicarmo Rocha Ferretti.

Dois escritos sobre o tambor de mina - um de uma pesquisadora e outro de um sacerdote da mina - são a base deste ensaio. Pretende-se mostrar como esses dois escritos indicam uma possibilidade de diálogo e construção de uma narrativa antropológica dialógica. Retomam-se análises já iniciadas em estudo anterior sobre as relações entre o campo intelectual e o campo afro-religioso maranhense (Abreu 2009). Tenta-se, assim, realizar o exercício de uma reflexão das relações entre diferentes saberes sobre o tambor de mina a partir de dois artigos, da antropóloga Mundicarmo Rocha Ferretti, ${ }^{2}$ e a resposta a seu texto, escrita pelo sacerdote da Casa Fanti Ashanti, pai Euclides Ferreira. A aparente ruptura nos dois textos tem como centro o filme Atlântico Negro - na Rota dos Orixás, premiado como documentário, que suscitou críticas e questionamentos da "suposta verdade etnográfica" que contém (Parés 1998-1999).

O texto Bebeu da Minha Fonte e Sujou a Minha Água, de pai Euclides Ferreira (2000), foi uma resposta ao texto acadêmico da antropóloga Mundicarmo Rocha Ferretti, intitulado Pureza Nagô e Tradição Africana do Maranhão (2000b). ${ }^{3}$ Ambos abordam os mesmos temas e questões: a construção da identidade africana de terreiros de mina em São Luís e no Maranhão a partir de um modelo representado pela Casa das Minas e pela Casa de Nagô; e as diversas e plurais nações que constituem as práticas rituais da Casa Fanti Ashanti, que construiu sua identidade e ancestralidade de uma forma flexível, dinâmica e plural em comparação com as casas-modelos, descritas nos estudos etnográficos do tambor de mina.

Essa perspectiva teórica não é nova no campo dos estudos sobre religiões afro-brasileiras de forma mais ampla. A obra de 1988, Vovó Nagô e Papai Branco, da antropóloga Beatriz Góes Dantas, é uma das primeiras incursões pelo tema.

I Trabalha-se aqui com a noção de campo de Pierre Bourdieu, para quem o espaço social é formado por diferentes campos que "são espaços estruturados de posição ou de postos cujas propriedades dependem das posições nestes espaços. Um campo se define entre outras coisas através dos seus objetos de disputas e dos interesses comuns a todos que o compõem" (Bourdieu 1983: 89).

2 Agradecimentos à antropóloga Mundicarmo R. Ferretti pela contínua possibilidade de diálogo na escrita deste texto.

3 Essa foi a versão apresentada nas X Jornadas sobre Alternativas Religiosas en América Latina: Sociedad y Religión en Tercer Milenio - Buenos Aires, entre 3 e 6 de outubro de 2000. Uma mesma versão do artigo foi publicada na revista Ciências Sociais e Religião/Ciencias Sociales y Religión, 3 (3), outubro de 2001 (ISSN: 15184463). 
Ao realizar trabalho de campo num terreiro nagô em Laranjeiras/Sergipe, essa autora questiona a construção da noção de pureza africana a partir do papel que antropólogos ocupam nos terreiros que pesquisam.

Nessa mesma perspectiva seguiu a obra La quête de l'Afrique dans le candomblé (1999) de Sthephania Capone, que a partir da noção de reafricanização analisa a importância dos estudos etnográficos no campo religioso afro-baiano. Destacando diferenças regionais observadas em terreiros de Salvador, essa autora questiona a escrita etnográfica que construiu os contornos dessa reafricanização, que considera uma busca permanente da África.

Este artigo busca, de um lado, compreender os conceitos e as teorias acionados por pesquisadora e pesquisado na relação construída no trabalho de campo; de outro, busca refletir sobre as questões do trabalho de campo a partir do diálogo entre esses dois textos que descrevem os elos entre o Benin e o tambor de mina do Maranhão. Quais dimensões de verdade epistemológica do trabalho de campo podem se destacar nesses escritos? O que ocorreu para que uma relação duradoura entre pesquisadora e informante, com resultados positivos para ambos, culminasse numa ruptura em função de uma mesma narrativa que ambos sustentam? Que acontecimentos estão envolvidos nesses escritos que contribuem para refletirmos sobre o trabalho de campo e sua dinâmica continuamente relacional e não hierárquica? Ambos, apesar do distanciamento após esses escritos, continuaram cultivando um respeito mútuo ao longo de suas, paradoxalmente, distintas e próximas trajetórias.

O trabalho de campo e a escrita etnográfica transformam em escrita a realidade apreendida da relação com o outro. Essa relação, dinâmica e em contínua atualização, torna-se ela mesma um desafio epistemológico para a antropologia como ciência da diferença. Nesse aspecto, os conceitos e teorizações devem ser situados considerando aquilo que Weber (1999) define como um tipo ideal, ${ }^{4}$ um modelo que o pesquisador não deve buscar alcançar, mas pode utilizar como mediador das análises e reflexões que elabora a partir das relações sociais estudadas.

Tanto o texto de Mundicarmo Ferretti como o texto de Euclides Ferreira contêm elementos extraídos de um tipo ideal de tambor de mina que se estabeleceu tanto no campo intelectual como no campo religioso afro-maranhense, a partir de duas casas de mina fundadas em São Luís: a Casa das Minas e a Casa de Nagô. Diante dessas duas casas, ou do que se estabeleceu como tipo ideal

4 Weber propõe o conceito de tipo ideal para explicar a função lógica e a estrutura de conceitos e categorias utilizados na análise e compreensão da vida social. O tipo ideal é uma simplificação e generalização da realidade com a qual se analisa os fenômenos sociais. Nesse sentido, o tipo ideal não visa esgotar todas as possibilidades de interpretações da realidade e se constitui de duas funções básicas: fornece um caso limitativo com o qual os fenômenos concretos podem ser contrastados; e serve de esquema para generalizações, que servem ao objetivo final da análise do tipo ideal, que é a explicação causal dos acontecimentos históricos (Weber 1999: 106-107). 
a partir delas nos estudos sobre o tambor de mina, os escritos da pesquisadora e do pai-de-santo entram em disputa confrontam e rivalizam. Porém, o fazem apoiando-se nos mesmos acontecimentos e narrativas que ligam o tambor de mina a África.

O discurso antropológico e o discurso de ressignificação da África de um pai-de-santo utilizam e sustentam suas narrativas a partir dos mesmos fatos, acontecimentos, memória e lembranças. Do mesmo modo que a antropóloga, o sacerdote sustenta sua pluralidade e tradição a partir de definições antropológicas. É nas entrelinhas desse rico conflito entre visões de mundo plurais - o da mina e o acadêmico - que a antropologia se inscreve buscando encontrar "semelhanças entre diferentes que se reconhecem iguais".

A dinâmica do trabalho de campo abre para o improvável. Assim, tanto o sacerdote pai Euclides é o pesquisador de campo que aciona memória, histórias e acontecimentos para defender a pluralidade da sua identidade africana, como Mundicarmo é a mineira que diante de atualizações da tradição, refirma a ontologia africana que diferencia o tambor de mina de outras práticas rituais de matriz africana. Seu texto indica que a narrativa que apresenta e interpreta é a mesma que se apresenta e circula no artigo do sacerdote.

\section{VERDADE E INTERPRETAÇÃO: NAÇÕES AFRICANAS E TAMBOR DE MINA}

Desde os estudos que remetem aos trabalhos fundadores de Nina Rodrigues e Artur Ramos sobre as religiões afro-brasileiras no âmbito nacional, e Octávio da Costa Eduardo e Nunes Pereira no campo de estudos afro-maranhenses, está em questão a ancestralidade africana. Esses primeiros estudos realizados no Maranhão, baseados em pressupostos evolucionistas e etnocêntricos, elegem como modelo de práticas africanas em São Luís/MA, a Casa das Minas e a Casa de Nagô.

Essas casas, como mostrado em estudo anterior (Abreu 2009), são as primeiras a serem estudadas, carregam com elas uma história temporal e cultural, foram fundadas no século XIX, chefiadas por mulheres e tidas como originais diante de outras casas de culto de voduns e orixás, em São Luís. Foram, ainda, descritas e visitadas por diversos pesquisadores, como Sérgio Ferretti, Pierre Verger, Roger Bastide, Nunes Pereira, Octávio da Costa Eduardo, entre outros.

Pode-se pensar com Weber (1999), que na construção do tambor de mina como objeto de estudo se conformou um tipo ideal cujos signos, símbolos, história e rituais estão associados a essas duas importantes casas de tambor de mina. Como tipo ideal essas casas confrontam e harmonizam tanto o campo religioso afro-maranhense como o campo intelectual. Além dessas casas, outras já extintas, como os Terreiro do Egito, Terreiro de Vó Severa, Terreiro de Cutim e, ainda em funcionamento, o Terreiro de São Benedito/Justino, foram 
descritas ou citadas na literatura sobre o tambor de mina (M. Ferretti 2000a, Abreu 2009).

Além desses terreiros, duas casas fundadas em meados do século XX, o Terreiro Iemanjá, de Jorge Itacy, e a Casa Fanti Ashanti, de Euclides Ferreira, foram estudadas, a partir da década de 1970, como terreiros que apresentam importantes características do tambor de mina em São Luís/MA. Mas, ao contrário dos terreiros do século XIX, não se fecharam à inovações. Seus líderes, ambos falecidos, são reconhecidos na sociedade civil mais ampla por apresentarem importantes trajetórias como sacerdotes da mina que, ao contrário das casas mais antigas, abriram-se para o diálogo não somente com outros terreiros de tambor de mina, mas também com outras práticas afro-brasileiras como, por exemplo, o candomblé.

Essa literatura clássica (Abreu 2009), baseada em obras como A Casa das Minas de Nunes Pereira (1970), As Religiões Africanas no Brasil - Contribuição a Uma Sociologia das Interpenetrações de Civilizações (vol. II), de Roger Bastide (1971), ou ainda Uma Rainha Africana em São Luis de Pierre Verger (1970), constrói uma narrativa etnográfica tendo como suporte metodológico a distinção entre sujeito-objeto, razão-subjetivação. Essa dualidade não é específica do tambor de mina, tornou-se um dos elementos a organizar os elos entre o discurso acadêmico, constituído como antropologia, e as práticas rituais de ancestralidade africana, que constituem o discurso acadêmico enquanto tal.

Nos conceitos em jogo, como identidade, nações africanas, ancestralidade africana, harmonizam-se, estranham-se e aproximam-se o mundo da pesquisadora e o mundo do sacerdote, ambos construídos a partir do tambor de mina. A técnica da observação participante e do trabalho de campo, assim, é determinante para a pesquisa antropológica, nela a narrativa circula, permitindo que a antropologia descreva a mina e, do mesmo modo, a dinâmica da mina assimila e transforma também a descrição etnográfica.

Os textos de Euclides Ferreira e Mundicarmo Ferretti descrevem fragmentos da dinâmica da construção e transformação da ancestralidade africana no tambor de mina.

Mundicarmo Ferretti realizou um longo trabalho de campo na Casa Fanti Ashanti, que já havia também sido estudada por Amália Barreto na década de 1970. Seu trabalho de campo e pesquisas nessa casa, iniciados na década de 1980, estenderam-se até os anos 2000, quando surgiram os dois artigos.

O trabalho de campo de Mundicarmo na Casa Fanti Ashanti teve como resultado sua tese de doutorado, Desceu na Guma - O Caboclo do Tambor de Mina em Um Terreiro de São Luís: A Casa Fanti Ashanti (2000a), inúmeros artigos publicados e apresentados em eventos, e ainda um CD intitulado Tambor de Mina, Cura e Baião na Casa Fanti Ashanti, lançado em 1991. Para que tal trabalho culminasse numa vasta produção acadêmica e intelectual é notório que havia uma relação de trabalho e reconhecimento por parte da pesquisadora e 
do pai-de-santo, líder da casa pesquisada. Ambos ocupam importantes posições nas suas trajetórias de pesquisadora e sacerdote, o que evidencia a relevância desses trabalhos para o reconhecimento social dos dois, em seus respectivos campos.

No texto Pureza Nagô e Tradição Africana do Maranhão, Mundicarmo Ferretti (2000b) retoma uma discussão presente desde o surgimento dos estudos das religiões afro-brasileiras, o elo com a África e a suposta tradição ou pureza africana dos terreiros afro-brasileiros, tendo como referência o que foi estabelecido a partir dos estudos das nações que fundaram o candomblé da Bahia. Essa perspectiva recebe críticas no campo intelectual desde a década de 1980 quando, por exemplo, Beatriz Góes Dantas, com base em trabalho de campo realizado em Sergipe, critica o que foi condicionado como nagô puro a partir do candomblé da Bahia, utilizado para classificar e definir o "grau de pureza e tradição africana" das religiões afro-brasileiras em sua totalidade.

No artigo "A Casa Fanti Ashanti: um grupo étnico?" (1982), Maria Amália Barreto inaugura a crítica aos estudos dos terreiros de tambor de mina a partir da busca de "pureza e tradição africana". Realizando pesquisa na Casa Fanti Ashanti de pai Euclides, Barreto questiona essa posição teórica e critica o conceito de nação utilizado na análise dos terreiros de identidade africana em São Luís/MA.

Barreto foi uma das primeiras pesquisadoras a indicar, realizando estudos sobre o tambor de mina, que o conceito de nações usado na literatura brasileira para definir este ou aquele modelo como ritual tradicional de uma certa nação não contribui para compreender a atualidade e realidade das religiões de matriz africana como símbolos e signos de ancestralidade africana e, tampouco, a diversidade presente tanto na Casa Fanti Ashanti como nos terreiros considerados modelo como, por exemplo, a Casa de Nagô.

Barreto (1982) denuncia o que chama de "artificialismo da categoria nação" para apreender as formas de atuação e construção de uma ancestralidade africana, importante tanto para o campo intelectual como para o campo religioso. Comparando dança, vestimentas cerimoniais e outros elementos rituais, mostra em seu artigo como a Casa das Minas, a Casa de Nagô e a Casa Fanti Ashanti apresentam semelhanças e também diferenças. Essa comparação leva à conclusão de que é impossível "definir, do exterior, uma fronteira étnica, ou de substituir o nome étnico através do qual o grupo se define, por uma listagem de características culturais constatáveis objetivamente" (1982: 14).

Barreto (1982), que segue as orientações teóricas de Barth, insiste que "um grupo étnico se define em relação a outros com os quais mantém contato e com os quais geralmente partilha uma série de dados culturais, mas em relação aos quais afirma sua diferença" (1982: 14). Sustentando-se numa definição de etnia como "um conjunto de representações e valores, embora tenha evidentemente uma realidade objetiva por base", convida-nos a pensar as diferen- 
tes etnias tal como se apresentam na atualidade, "com histórias específicas, onde condições e fatores particulares devem ser levados em consideração" (1982: 14).

Nesse contexto teórico, Barreto considera que a Casa Fanti Ashanti, apesar de tentar afirmar-se no campo religioso a partir de muitas e diferentes nações, antes de tudo pode ser vista a partir de uma outra perspectiva: uma casa cuja história se sustenta também numa ideologia (Barreto 1982: 15). Esta ideologia é a busca contínua de elo com a África e a ancestralidade africana, como pai Euclides ressalta ao longo do seu texto anos depois.

Segundo Mundicarmo Ferretti, que reconhece a dificuldade em definir a história de um terreiro a partir da ideia de nação ao citar tanto Beatriz Góes Dantas como Maria Amália Barreto, "no Maranhão, três casas construíram suas identidades tomando especialmente como referência uma 'nação africana': a Casa das Minas-Jeje, a Casa de Nagô e a Casa Fanti Ashanti. De acordo com a tradição oral, as duas primeiras foram fundadas bem antes da promulgação da 'Lei Áurea', a Casa das Minas por Maria Jesuína, dahoemana que teria entrado no Maranhão como contrabando, e a Casa de Nagô, por (nagô) Josefa e Joana (cambinda) [...]" (M. Ferretti 2001: 76).

Porém, para Mundicarmo Ferretti, enquanto as primeiras, fundadas e chefiadas por mulheres, apresentam uma identidade mais rígida e fechada a inovações, a Casa Fanti Ashanti é mais aberta às inovações, transformações e diálogos com diferentes nações:

"A Casa Fanti-Ashanti foi aberta com o nome 'Tenda de São Jorge Jardim de Ueira’ em 1958, por Euclides Ferreira, ligado ao Terreiro do Egito, matriz da Mina fanti-ashanti (já desaparecido). Segundo informação por ele recebida de sua mãe-de-santo, o Terreiro do Egito foi fundado em 1864, por Basília Sofia, natural de Cumassi (Gana). Alguns anos após o falecimento de sua mãe-de-santo, Pai Euclides ligou-se a terreiros de Xangô de Pernambuco, passando a definir-se como jeje-nagô, mas a Casa continuou sendo denominada Fanti-Ashanti, nome pelo qual tornou-se mais conhecida. A partir de 1980 a Casa passou a adotar, além da Mina, o Candomblé ketu (de estilo baiano) e, no final de 1997 após participação no vídeo 'Na rota dos orixás', de Renato Barbieri, vem sendo também apresentada como continuadora da tradição dahomeana (jeje) no Brasil, enfatizando outro aspecto de sua identidade africana múltipla." (M. Ferretti 2001: 77)

De algum modo, a construção do campo de estudos e a dinâmica do campo religioso, ao elegerem a Casa das Minas e a Casa de Nagô como tipos ideais, estabeleceram valorações que fortalecem a construção e a afirmação de uma ancestralidade africana cujos símbolos, signos, rituais e transmissão buscam evidenciar constantemente o elo com a tradição dahomeana. Daí a 
impossibilidade de afirmação de identidade a partir do tambor de mina sem confrontar verdades estabelecidas, como o faz a Casa Fanti Ashanti ao acionar suas diferentes nações, comprovadas na história e na luta do seu líder religioso no campo das religiosidades de ancestralidade africana.

Pai Euclides considera que a atribuição de uma identidade fluida e em contínua construção para sua casa, tal como indica Mundicarmo Ferretti (2000b, 2001), é uma crítica aos seus deslocamentos e identidades múltiplas, que entre outras coisas definem a história do seu legado religioso. Para ele, sua condição de mineiro de origem fanti, babalolorixá do xangô, candomblé ketu ou, ainda, sua vinculação a caboclos, não contradiz sua história e, tampouco, seu percurso na mina, como afirma:

"A minha vida sacerdotal teve início no antigo terreiro do Egito (ilê Nyame) fundado em 12 de dezembro de 1864 por Massinokô Alapong (Basília Sofia de Cumassi (Gana) - informação repassada por minha mãe de santo Maria Pia dos Santos Lago (Akô-Vonunkô - de acordo com a tradição oral, a mesma tradição que fundamenta a certeza de fundação da Casa de Nagô Abioton e a Casa das Minas Jeje, antes da promulgação da Lei Áurea em 1888.

Após um longo período de aprendizado (apesar de continuar aprendendo) foi me dado permissão de abrir a casa Fanti-Ashanti em 1958. Posso garantir que todo o sistema religioso desenvolvido nesse terreiro de culto a Orixás, Voduns, Caboclos, Gentil e Nobres é fruto do que aprendi, experimentei e vivenciei nos terreiros do Egito e da Turquia fundado em 23 de junho de 1889, pela Ialorixá Anastácia Lúcia dos Santos (Akisi Obenã) além da convivência com os mais velhos durante toda a minha vida." (Ferreira 2000: 2)

Nas análises elaboradas por Mundicarmo Ferretti circula a mesma ideia presente nas memórias de Euclides Ferreira, ambos acionam fatos e acontecimentos registrados pela transmissão oral sobre a construção da Casa das Minas, Casa de Nagô e Casa Fanti Ashanti. Podemos, assim, interpretar que os dois acionam os mesmos elementos em suas discursividades aparentemente distintas. Seus textos reconstroem como história oral e escrita etnográfica, a identidade e origem das casas de culto de tambor de mina do Maranhão.

Enquanto a Casa das Minas e a Casa de Nagô são tidas como mais fechadas a inovaçóes e a entrada de novos elementos em suas identidades, a trajetória da Casa Fanti Ashanti é marcada por deslocamentos. Porém, essas chamadas casas tradicionais são também marcadas por reconstruções e deslocamentos, pois não se pode afirmar que não tenham elaborado transformações e mudanças em suas trajetórias de matriz africana.

O que se observa, por exemplo, no percurso descrito por Mundicarmo Ferretti sobre a Casa de Nagô, que apresenta elos e semelhanças com a Casa das 
Minas, apesar das diferentes nações africanas associadas às origens de ambas; e apresenta ainda diferenças notáveis em relação ao nagô, do qual seria mais próximo em função também da nação iorubana que a define. Em consequência disso, Maria Amália Barreto afirma que "A Casa de Nagô tem características próprias, não se confunde com a Casa das Minas, mas não se assemelha muito a terreiros nagô tradicionais existentes em outros estados" (1982: 126).

Barreto (1982) indica que os fatores étnicos que constituem um grupo são interativos e relacionais. Nesse contexto, as identidades são contingentes, construções políticas, acionadas, construídas e fortalecidas nas relações. Essa proposição de Barreto é notável no diálogo que pai Euclides Ferreira e Mundicarmo Ferretti estabelecem nos seus escritos ao discorrerem também sobre o conceito de nação tendo como realidade empírica a Casa das Minas, a Casa Fanti Ashanti e a Casa de Nagô.

Mundicarmo Ferretti (2001: 81) relata que pai Euclides herdou o Baião do Terreiro do Egito, festa que era realizada na época de sua mãe-de-santo e que ele integrou ao seu terreiro após o fechamento daquele terreiro. Como descreve também pai Euclides:

"Após o declínio do Terreiro do Egito, incorporei ao calendário da casa ritual 'baião de princesas' que era próprio do referido terreiro. Ao ver este fechar as portas, não poderia deixar uma importante tradição ficar nas lembranças do passado, eu, como filho do Egito me achei no direito de executar este ritual, já que eu tinha (e tenho) preparo suficiente e casa aberta para seu desenvolvimento." (Ferreira 2000: 6).

Percebe-se, assim, que o diálogo entre os dois textos, ainda que em aparente contradição, funciona a partir de elementos históricos e culturais semelhantes que sustentam a relação entre ambos. Enquanto no texto de Mundicarmo Ferretti esses aspectos são destacados para indicar o distanciamento em relação à forma de funcionamento do modelo ideal, estabelecido na literatura a partir da Casa das Minas e Casa de Nagô, pai Euclides descreve os mesmos elementos para reafirmar seu laço com a mina a partir da nação Fanti Ashanti, e sua incessante busca de continuidade das tradições de matriz africana no Maranhão. O que uma vez mais o diferencia das casas modelos, pois, como descreve Mundicarmo Ferretti, ambas, a Casa das Minas e a Casa de Nagô "tentaram evitar a proliferação de terreiros de Mina” (M. Ferretti 2001: 78).

Os deslocamentos identitários e as várias nações com as quais estão associadas a trajetória de pai Euclides se comprovam por meio de alguns fatos que tanto Mundicarmo Ferretti como pai Euclides descrevem como verdade histórica e cultural da mina. Nesse sentido, a relação com o Terreiro do Egito lhe confere o laço com a nação Fanti Ashanti, pois nesse terreiro pai Euclides 
recebeu pela primeira vez o Rei dos Mestres, caboclo sincretizado com Oxalá no candomblé, e com o vodun Lissá na mina.

Além desse elo com o tambor de mina, pai Euclides apresenta interessantes elos com a Casa das Minas e a Casa de Nagô. Assim, por exemplo, tanto ele como Mundicarmo Ferretti descrevem que ele fora dado, ainda na barriga da mãe, ao vodun Lissá na Casa das Minas, quando certa vez sua mãe assistia a um ritual nessa casa. Esse laço espiritual é marcado também pela convivência de pai Euclides com mulheres da Casa das Minas e da Casa de Nagô, como ambos indicam em seus escritos:

"É bom lembrar que Pai Euclides teve ao seu lado durante muitos anos, uma pessoa que, além de ser 'guia' (mãe pequena) do Terreiro da Turquia, um dos mais antigos de São Luís, onde ele teve seus caboclos confirmados, era muito ligada a Casa das Minas: Maria dos Remédios. Teve também aproximação com várias pessoas da Casa de Nagô, entre as quais Maria Leoa, que morou em sua casa, quando ele era criança, e que o levou algumas vezes para lá em noites de toque." (M. Ferretti 2000b: 6)

"A Casa Fanti Ashanti por vários anos foi visitada por algumas vodunsis da Casa das Minas entre elas: Dilú, Deni, Maria Rouxinha, Celeste, Justina, Edwirgem, Elza, Amancinha e Neusa de Sogbô, essa até passava semanas na minha casa mas confesso que todas essas vodunsis foram fiéis a sua Casa Matriz e nunca transmitiram nada para mim, assim como, Maria dos Remédios do Terreiro da Turquia que desde menina viveu na Casa das Minas a partir de janeiro de 1966 até 10 de junho de 1980 conviveu na Casa Fanti Ashanti e foi bastante digna em não me repassar o que sabia da Casa das Minas, no entanto em relação as práticas do Terreiro da Turquia onde sou sucessor desde de março de 1972, foi quem ainda me repassou algumas coisas." (Ferreira 2000: 2).

Esses laços com as casas de mina definidas como tradicionais pela literatura antropológica, não impediram que pai Euclides entrasse em contato com o xangô e o candomblé, no qual se preparou a partir da ligação espiritual com pais-de-santo de Recife/PE, como ambos descrevem em seus escritos. No entanto, enquanto Mundicarmo Ferretti descreve esses acontecimentos para indicar os diversos e possíveis deslocamentos de pai Euclides que o distanciam da mina, que o levam da mina ao xangô e deste ao candomblé, pai Euclides o faz para indicar que é fruto de três raízes africanas, portanto, um legítimo herdeiro do Axé-Etá, como se define (Ferreira 2000: 7).

Essa busca incessante de reconhecimento e tradições africanas que pai Euclides, aliás, não nega, ao contrário reafirma quando utiliza argumentos nos quais defende seu interesse pela relação com a África, tornou-se o ponto de 
conflito entre os dois escritos a partir do filme Atlântico Negro - na Rota dos Orixás. Antes de passar-se às discussões específicas dos temas presentes no filme, faz-se necessário elaborar algumas reflexões presentes nos dois escritos.

Inicialmente, é interessante destacar como a reconstrução das práticas rituais de matriz africana a partir de um elo com a África se torna um pressuposto de reconhecimento tanto no campo religioso afro-maranhense como no campo intelectual. Tanto Euclides Ferreira quanto Mundicarmo Ferretti descrevem fatos, acontecimentos e relatos que buscam, de algum modo, um elo "verdadeiro, autêntico, único" com a África. Contudo, ambos em seus escritos, criticam essa necessidade de afirmação contínua da ancestralidade africana que acionam em seus discursos.

Porque tanto a pesquisadora como o sacerdote, dotados de conhecimento, leituras e relações de trabalho, parecem ignorar essa crítica em seus textos, apesar de simultaneamente reconhecerem os limites dessa reconstrução a partir de um ideal de autenticidade africana baseado na ideia de nação? Esse pode ser considerado o ponto de aporia entre o campo intelectual e o campo religioso afro-maranhense? $\mathrm{Ou}$, ao contrário, pode ser interpretado como um ponto de convergência entre esses dois campos, na medida em que a busca de reconhecimento nesses dois campos se origina dessa suposta autenticidade africana?

Como ponto de convergência entre os dois campos, o elo com a África possibilita a busca de autenticidade e reconhecimento nas relações estabelecidas neles. Nesse sentido, o discurso de ambos se sustenta numa igualdade de saberes e conhecimentos organizados através das relações entre o tambor de mina, a ancestralidade africana e a escrita etnográfica, relações construídas através do trabalho de campo.

O FILME ATLÂNTICO NEGRO - NA ROTA DOS ORIXÁS:

\section{A VERDADE EM DESLOCAMENTOS}

Pode-se afirmar que os escritos de Mundicarmo Ferretti e Euclides Ferreira se originaram de uma questão que está diretamente relacionada à antropologia, contudo, não é eminentemente ou puramente posta como saber antropológico. Ambos escrevem a partir dos efeitos causados pelo filme Atlântico Negro - na Rota dos Orixás, dirigido por Renato Barbieri. De um lado, como afirma Luis Nicolau Parés na Revista Afro-Ásia (21-22 - 1998-1999), o filme teve uma repercussão positiva, trata dos elos entre a África e o Brasil, frequentemente esquecidos. De outro lado, causou um certo mal-estar ao ser premiado e coroado como um documentário etnográfico, cuja verdade etnográfica é facilmente contestada.

A resenha elaborada por Parés na Revista Afro-Ásia tece críticas amplas sobre o fato de o filme ser apresentado como um documentário. As questões postas 
por ele nesse artigo permeiam tanto o escrito de Mundicarmo Ferretti como o de Euclides Ferreira. Para Parés, o filme tem seus méritos e merece destaque pelo tema que aborda. Contudo, os equívocos de ser lançado como um documentário devem ser discutidos, pois podem levar a interpretações que contribuem para estigmatizar e valorar de forma simplista as religiões de matriz africana, em suas diversidades e pluralidades (Parés 1998-1999).

O documentário trata das relações históricas e culturais que existem entre o Brasil e a África, com ênfase nos aspectos das religiões dos orixás. Para Parés, o filme tem um alto potencial comunicativo. Conta com a participação, através de entrevistas, de eminentes e significativos especialistas do tema - antropólogos, historiadores e líderes religiosos - o que lhe confere um caráter intrínseco. Executado em formato de documentário televisivo, possui uma boa qualidade técnica, domínio da linguagem cinematográfica, boa fotografia e grande plasticidade (Parés 1998-1999: 367).

Parés situa a proposta ideológica do filme a partir do termo "Atlântico negro", cunhado por Paul Giroy na obra The Black Atlantic: Double Consciousness and Modernity, na qual aborda a questão da diáspora da comunidade caribenha no Reino Unido, e com relevante aceitação nos meios intelectuais afro-americanos. Parés indica ainda que o caráter abrangente desse termo resulta num paradigma conceitual que permite reformular muitas das dicotomias surgidas em torno da dualidade entre a África e suas diásporas transatlânticas (Parés 1998-1999: 367).

É a história desse intercâmbio, primeiro de mensagens gravadas em vídeos e depois a troca de presentes rituais entre os dois líderes religiosos - pai Euclides, babalorixá da Casa Fanti Ashanti, em São Luís/MA, e o vodunon Avimanjenon, chefe do Templo de Avimanje, em Uidá - que Parés considera a cena que pontua e demarca o discurso substantivo do filme (Parés 1998-1999: 368). Essa cena, a primeira do filme, cronologicamente foi a última gravada.

A abertura emblemática, como a define Parés, introduz uma série de sequências em que através da voz de um narrador, comentários dos entrevistados e imagens de festas ora do Benin, ora do Brasil, vão desvelando os laços e relações entre África e Brasil. Segundo Parés (1998-1999: 368), “faz-se uma apresentação, ou melhor, uma representação da história e dos vínculos culturais entre os dois países".

De acordo com Parés, os conteúdos apresentados no documentário são variados, mas orbitam em torno de três grandes temas: a religião dos orixás, o tráfico de escravos e a comunidade do Agudá (descendentes de escravos africanos retornados a África) (Parés 1998-1999: 369). Para esse autor, as imagens de diversas atividades rituais que dão suporte ao discurso oral são desconexas e estão montadas num ritmo rápido, que em algum momento leva a certa confusão. Quando se fala, por exemplo, do culto dos orixás e voduns, mostra-se imagens dos eguguns, culto de origem iorubá dos ancestrais, que não é 
considerado propriamente culto dos orixás; quando se fala de Exu mostra-se imagens de um Heviosso, vodun do trovão.

As imprecisões, para Parés, podem passar despercebidas aos olhos de um não especialista, e poderiam ser consideradas licenças criativas a serviço da narrativa verbal, mas são esses detalhes que põem em questão a fidelidade etnográfica do documentário e que podem suscitar críticas dos participantes da religião. Imagens desse contexto em Uidá são alternadas com imagens de Salvador/BA e São Luís/MA, grupos seculares como Ilê Aiyê são justapostas às festas religiosas do tambor de mina do Maranhão e do candomblé da Bahia (Parés 1998-1999: 369).

De acordo com Parés, essa justaposição de imagens leva o espectador leigo a pensar erroneamente que, sendo música e dança, é tudo a mesma coisa. Seguem imagens das casas mais importantes do candomblé baiano como Gantois, Axé Opô Afonjá, com depoimentos da babalorixá mãe Estela, que descreve a genealogia dos orixás desse terreiro. Surgem também imagens de São Luís/MA, mais especificamente da Casa das Minas, onde dona Deni, zeladora da casa, fala sobre a fundadora desse terreiro, a africana Maria Jesuina, ou Ná Agotimé, que Pierre Verger levantou a hipótese de ser a rainha daomeana mãe do Rei Guêzo, vendida como escrava pelo rei Adandonzan (Parés 1998-1999: 370).

Após o ir e vir entre as duas costas do Atlântico, no qual o espectador é informado de variados aspectos históricos e culturais, segue a parte, talvez a mais original do ponto de vista de um documentário segundo Parés, em que se mostra o intercâmbio de mensagens audiovisuais entre os líderes religiosos do Benin e do Brasil (Parés 1998-1999: 371).

Para Parés, esse evento funciona, na narrativa do filme, como evidência e confirmação de que o diálogo entre as duas bandas do mar (mesmo que gerenciado pela equipe do filme) segue vivo. Pai Euclides e a mãe pequena do terreiro cantam uma cantiga em fon em São Luís/MA. Intercalam-se imagens do Avimanjenon e do Adjahô Houmassé frente ao monitor de vídeo vendo essa mensagem, o primeiro no seu templo de Uidá; o segundo, na sua residência em Abomey. Significativamente, o Avimanjenon diz que entendeu a cantiga, e o velho Adjahô também a reconhece e começa a cantá-la, o que confere a esse belo momento um tom emotivo (Parés 1998-1999: 371).

O Avimanjenon responde com outra mensagem audiovisual que inclui uma outra cantiga, e um presente, um bastão cerimonial que a equipe do filme leva ao Maranhão. Pai Euclides recebe o presente de forma ritual, com várias filhas da casa vestidas de Tobossi (a moda do jeje maranhense), jogando o obi e lavando o bastão com uma mistura de folhas maceradas (Parés 1998-1999: 372).

De acordo com Parés, esse emblemático intercâmbio é considerado pelo narrador como um exemplo do "respeito e admiração mútua que o Brasil e a África mantêm entre si” (Parés 1998-1999: 372). Contudo, é nesse ponto que 
a linguagem cinematográfica, com sua inevitável construção e recorte da realidade, joga a favor da intencionalidade ideológica do filme. Pois o documentário, por exemplo, não fala que foi pai Euclides quem pediu o bastão cerimonial, e foi a equipe do filme que teve que pagar o presente.

Parés esclarece ainda, numa nota de rodapé, que o documentário não explica a natureza da relação preexistente entre pai Euclides e o Avimanjenon, que se iniciou em 1995 quando, após uma viagem ao Benin, Parés levou uma carta e uma fotografia do Avimanjenon, bem como um vídeo das festas celebradas no seu templo de Uidá. Esse primeiro contato foi seguido por uma troca de cartas em francês e outras fotografias (Parés, 1998-1999: 372).

De acordo com Parés, a recepção do bastão cerimonial foi obviamente representada para ser filmada e não parece responder a nenhuma tradição ritual da casa. O que novamente evidencia a capacidade que tem a produção de um documentário para alterar ou gerar novas realidades. Essa capacidade intrínseca e manipuladora do filme não deve ser necessariamente negativa, já que, às vezes, pode gerar situações capazes de revelar informações que não estariam acessíveis de outro modo (Parés 1998-1999: 372). Contudo, continua Parés, do ponto de vista etnográfico e a serviço do rigor científico, é preciso que o documentário seja explícito quanto às suas estratégias de construção no processo de representação, já que por trás das imagens montadas existe sempre outra história que não é contada (Parés 1998-1999: 372).

A história não contada é, por exemplo, a que se evidencia nos escritos do sacerdote Euclides Ferreira e da pesquisadora Mundicarmo Ferreti. Esta última, ao se deter nos deslocamentos de pai Euclides Ferreira. questiona, ainda que sutilmente, sua figura de guardião da mina tal como aparece no documentário e, mais especificamente, na troca de presentes com o sacerdote do Benin. Pai Euclides Ferreira, ao responder a essas críticas, não deixa de mostrar que o que se define como modelo de tambor de mina a partir da Casa das Minas e da Casa de Nagô é uma construção tanto quanto sua troca de presentes com o sacerdote do Benin.

As questões abordadas no filme que se tornam objeto de diálogo-crítico entre os dois textos circulam em torno de alguns temas como: a troca de presentes entre os dois sacerdotes, cena construída para o documentário; a semelhança entre a experiência de dona Celeste ao entoar um cântico africano no Benin e a cena representada no filme pelos dois sacerdotes, que envolve o cântico africano cantado por pai Euclides; e as ações (rituais ou não) elaboradas por pai Euclides em seu terreiro, a partir de sua participação no filme.

A troca de presentes encenada no filme não aborda o início das relações estabelecidas entre pai Euclides e o sacerdote do Benin. Anteriores ao filme, essas relações se iniciaram em 1999 a partir das ações de um pesquisador, Luis Nicolau Parés. Não foi pai Euclides nem o sacerdote do Benin que forjaram esse diálogo anos antes, foi alguém do campo intelectual, o que indica uma vez 
mais a necessidade desse campo em construir provas, históricas e culturais, que reafirmem e sustentem o elo das práticas de matriz africana no Brasil, com a África. Se agentes do campo intelectual buscam esse elo continuamente, porque agentes do campo religioso não o fariam, uma vez que se trata da história mítica e ritual de suas origens?

A cena do filme na qual pai Euclides canta em língua fon uma música reconhecida pelo sacerdote do Benin apresenta semelhanças com a experiência de dona Celeste, da Casa das Minas, numa viagem que realizou ao Benin. Como conta Pierre Verger no prefácio da segunda edição do livro Querebentã de Zomadônu, de Sérgio Ferretti:

"Entre os momentos mais comoventes que tive a oportunidade de presenciar, na República do Benin, ex-Daomé, em 1993, gostaria de citar os que assisti em Ouidah, durante as celebrações realizadas neste lugar para comemorar as antigas relações estabelecidas entre a África e o Novo Mundo na época do tráfico de escravos.

Entre os participantes dessa manifestação figurava Sérgio Ferretti e Mundicarmo Ferretti, acompanhados de dona Celeste, da Casa das Minas de São Luís do Maranhão.

Durante nossa visita ao monumento elevado, no percurso do caminho que liga a cidade à praia de embarque dos infortunados escravos, dona Celeste teve a inspiração de cantar certos hinos africanos conhecidos na Casa das Minas de São Luís do Maranhão.

Um milagre aconteceu, pois a gente de Ouidah conhecia essas cantigas e se juntou em coro a ela, com acompanhamento de palmas e bailados. Era o reencontro, após dois séculos, de irmãos e irmãs que foram separados $[\ldots]$ Pierre Verger." (S. Ferretti 1996: 12).

O que se observa nas semelhanças do vivido na viagem ao Benin e o encenado como filme é a ação dos intelectuais na busca incessante do elo entre o tambor de mina e a África. Da mesma forma que o elo de pai Euclides com o sacerdote vodunon Avimanjenon fora construído por ações de Nicolau Parés e posteriormente encenado no filme, a ida de dona Celeste ao Benin teve a participação central de intelectuais como Pierre Verger e Sérgio Ferretti (S. Ferretti 1996). O que evidencia a relação intrínseca entre o campo intelectual e o campo religioso a partir do elo com a África.

Porque o diálogo iniciado entre pai Euclides e o sacerdote vodunon Avimanjenon, incentivando por agentes exteriores ao campo religioso, seria menos verdadeiro que a viagem feita por dona Celeste, com intelectuais como Pierre Verger e Sérgio Ferretti? Porque a cena vivida por uma vondunsi da Casa das Minas, relatada no prefácio de um livro, não poderia ser a inspiração para a produção do filme? 
Novamente o que se observa nessa cena remete aos vínculos do tambor de mina com o Benin tanto na experiência descrita por Verger e vivenciada por dona Celeste, como na cena reproduzida no documentário com o objetivo de destacar esses elos. É interessante observar o comentário de pai Euclides, em seu texto, a respeito dessa suposta semelhança entre o vivido e o encenado no filme:

"Quando a autora do texto 'PUREZA NAGÔ E NAÇOES AFRICANAS NO TAMBOR DE MINA DO MARANHÃO’ cita a participação da vodunsi Maria Celeste ter cantado (1992) no Festival de Cultura de Vodun em Ouidah e o cântico ter sido entoado conjuntamente por vários beninenses isso não é de se admirar, afinal de contas, dona Celeste sabe perfeitamente os cânticos de voduns e conhece sua raiz desde que ingressou na Casa das Minas. Afirmo, no entanto, que não tenho como reproduzir esse momento Ouidah quando a mesma cantou, pois eu não estava lá, eu não vi nada a respeito e nem ouvir, e muito menos presenciei algum depoimento sobre esse fato." ${ }^{\prime 5}$ (Ferreira 2000: 10).

Não deixa de ser curioso que pai Euclides, que em diversas passagens do seu artigo se intitula como um leitor e pesquisador interessado nos vínculos com a África, não tenha lido ou mesmo entrado em contato com a obra de Sérgio Ferreti, na qual Pierre Verger descreve essa cena. Embora seja enfático em dizer que desconhece esse acontecimento porque não estava nessa cena, não se pode desconsiderar seus laços com pessoas da Casa das Minas e com os pesquisadores envolvidos nessa experiência com dona Celeste e a pesquisadora Mundicarmo Ferretti, que em 1992-1993 já realizava pesquisas na Casa Fanti Ashanti. ${ }^{6}$ Porém, é necessário destacar que ainda que conhecesse essa cena, pai Euclides não teria como interferir no roteiro de um filme a ponto de exigir sua reprodução, ou não, num documentário.

Na busca de vínculo com a África, os cânticos ocupam importante simbologia. São eles que se destacam tanto na visita de dona Celeste ao Benin como na cena do filme com pai Euclides. Em ambas, o reconhecimento de cânticos em língua fon entoados por pessoas iniciadas no tambor de mina se torna a experiência emocionante de elo entre os voduns do Maranhão e os voduns do Benin. Na cena do filme, porém, não fica claro que pai Euclides entoou um cântico que lhe foi ensinado por um estudante do Benin, como destacam tanto Mundicarmo Ferretti como Euclides Ferreira em seus textos.

Ambos explicam que o estudante Olivier Gbegar ensinou o cântico entoado por pai Euclides no filme. Esse e outros cânticos que fazem referência à mãe do

6 Em 1993, ocorreu o evento intitulado Festival de Cultura do Vodun Ouidah/92. 
Rei Guezo vendida como escrava ${ }^{7}$ foram cantados também por sacerdotes do Benin que participaram do colóquio "Sobrevivências das Tradições Religiosas Africanas no Caribe e na América Latina”, realizado pela UNESCO em 1985. Durante esse evento, alguns terreiros de São Luís realizaram toques e receberam sacerdotes do Benin que participavam do colóquio. Entre essas casas estavam a Casa Fanti Ashanti e a Casa das Minas. As duas receberam sacerdotes e, em ambas, esse cântico e outros também foram entoados por pessoas do Benin (M. Ferretti 2000b: 9).

O que se destaca novamente nesses acontecimentos é a posição dos intelectuais em realizar um diálogo entre sacerdotes, cânticos, objetos rituais, trajetórias de sacerdotes do Benin e do Maranhão. Esses laços, assim, reafirmam os vínculos entre o tambor de mina do Maranhão e o culto dos voduns do Benin. É nessa direção que segue o roteiro do filme ao reapresentar e encenar experiências e diálogos nos quais o campo intelectual ocupa uma importante posição.

Pai Euclides aprendeu esse cântico num momento mais recente com um estudante do Benin, da mesma forma que aprendeu e entoa outros cânticos africanos em sua trajetória de sacerdote da mina ou do candomblé. E, do mesmo modo, dona Celeste aprendeu cânticos ao longo da sua trajetória como vodunsi da Casa das Minas, mas esta casa também não se furtou de receber o mesmo estudante para entoar cânticos do Benin durante o colóquio. O que se destaca nessa experiência vivenciada e encenada pelos agentes do campo religioso, são as ações de agentes do campo intelectual ocupados em vivenciar, ressignificar e simbolizar esse vínculo com a África, ao elegerem significantes como cânticos e trajetórias como símbolos de comprovações de elos entre o tambor de mina e os voduns do Benin.

Além do cântico, o bastão cerimonial, que na cena do filme é um presente do sacerdote do Benin para pai Euclides, que realiza um ritual para recebê -lo, foi comprado pela produção do filme, como destaca Parés (1998-1999). Porém, esse detalhe não é perceptível ao espectador, o que leva Mundicarmo Ferretti a elaborar uma crítica ao ritual construído com tal objetivo, uma vez que nele rituais da mina são associados a elementos rituais de outras práticas como o candomblé.

Embora a produção tenha comprado o bastão e forjado esse objeto como um presente ritualmente recebido, o fez para legitimar o roteiro de um filme que muitas vezes nem a própria produção sabe os caminhos que seguirá. Como afirma Parés, foi quando chegou ao Benin e descobriu que a cantiga era

7 Importante destacar que os cânticos entoados pelas vodunsis da Casa das Minas, por pai Euclides da Casa Fanti Ashanti, pelos sacerdotes do Benin que vieram para o congresso da UNESCO e pelo estudante beninense que fazem referência a Nã Agotimé não são um único cântico que se repete com esses diversos agentes. Como destacou a pesquisadora Mundicarmo Ferretti quando da leitura deste artigo, essa rainha é citada em diferentes cânticos, entoados nesses diferentes lugares. 
reconhecida por várias pessoas que Barbieri se deu conta da importância do material gravado em São Luís/MA. O que "o levou a concentrar seus esforços no Benin e não na Nigéria, como estava planejado inicialmente, e, depois, dar especial relevância a essa parte na estrutura do filme, o que também não figurava no roteiro original" (Parés 1998-1999: 372). ${ }^{8}$

A relação entre a mina e o entendimento antropológico sobre essas práticas rituais, assim, vai se impondo diante de um roteiro já aparentemente pronto e fechado, diante dela a produção do filme vai reconstruindo imagens, cenas e modificando os locais de filmagem. Nesse sentido, podemos interpretar que os elos entre os voduns do tambor de mina e Benin vão se impondo como narrativa diante de um roteiro previamente estabelecido, e este vai se reorganizando, transformando-se e se deslocando, de acordo com os vínculos estabelecidos como cultura e história da ancestralidade africana do tambor de mina.

As imagens do documentário remetem tanto às casas modelo, Casa das Minas e Casa de Nagô, como à construção plural da identidade da Casa Fanti Ashanti. A preparação de um ritual no qual une elementos como búzios, associado ao candomblé, e as vestimentas de tobossis da mina, ou ainda a referência a Exu não contradiz a história e a trajetória de pai Euclides como sacerdote que constrói e reconstrói sua identidade plural.

Ao contrário, o filme vem exatamente afirmar a posição do sacerdote Euclides Ferreira como detentor de uma identidade étnica plural, e ideológica, como a define Barreto (1982). O discurso intelectual não consegue compreender ou analisar essa identidade estando preso aos cânones que estabeleceu como modelo e tipo ideal do tambor de mina, como já indicava Maria Amália Barreto. Assim, o discurso de pai Euclides como mineiro e pensador de sua ancestralidade e religiosidade é também uma narrativa antropológica.

Mundicarmo Ferretti, como pesquisadora da mina, sente a necessidade de questionar as ações intencionais reproduzidas no filme, estas elegem Euclides como guardião do culto dos voduns no Maranhão. Do mesmo modo, o sacerdote Euclides Ferreira, pelos elos com a mina evidentes em sua trajetória, constrói sua identidade mineira reproduzindo imagens fílmicas que confirmam o elo entre a África e o Brasil, o tambor de mina e a prática ritual dos voduns, no Benin e no Maranhão.

A experiência vivida pela guardiã da Casa das Minas, cuja ida ao Benin também pode ser interpretada como uma reafirmação dos elos entre o tambor de mina e o Benin, está presente também na reprodução elaborada no filme a

8 Vale ressaltar que o diretor Renato Barbieri esteve na Casa das Minas num dia de toque de tambor para solicitar permissão para realizar o filme. Porém, os voduns da casa não aceitaram, como informa Mundicarmo em seu artigo, e relataram-me posteriormente, em conversas informais, os pesquisadores Sérgio Ferretti e Mundicarmo Ferretti, presentes também nesse toque. Foi a partir dessa negativa dos voduns da Casa das Minas que a produção do filme optou por realizar o filme na Casa Fanti Ashanti. 
partir da figura de pai Euclides, cuja identidade em contínua elaboração, não está ligada somente à mina. Esses fatos evidenciam que a ancestralidade da Casa das Minas, assim como a ancestralidade da Casa Fanti Ashanti são construções sociais originadas da diáspora africana.

Percebe-se, assim, que a problemática em torno dos dois escritos se dá em consequência dos acontecimentos narrados e descritos em situações diversas. Contudo, poderiam esses dois agentes, posicionados em campos inter-relacionais, furtarem-se de questionar os acontecimentos descritos e narrados por eles em seus respectivos textos? Não é exatamente a coragem e a audácia de o terem feito que confirmam suas posições em seus respectivos campos? Poderia Mundicarmo Ferretti não se posicionar como pesquisadora do tambor de mina e da Casa Fanti Ashanti, ainda que esse posicionamento exigisse dela uma crítica à trajetória do sacerdote e à casa que ela pesquisou ao longo de sua vida acadêmica? Poderia pai Euclides interferir na produção de um documentário que reconstrói um elo entre o tambor de mina e o Benin, com o qual ele se identifica?

Mundicarmo Ferretti fez a escolha por uma defesa do tambor de mina que privilegia o modelo ideal estabelecido nos cânones dos estudos do tambor mina, que elegeram a Casa das Minas e a Casa de Nagô como os dois importantes "centros de tradição dahomeana no Maranhão". Enquanto pai Euclides, para defender seu percurso e trajetória plural de vínculo com a mina, muniu-se de um discurso antropológico que fornece a base para a sua decisão em participar de um documentário que visa destacar e evidenciar seu papel de guardião do tambor de mina do Maranhão. Ainda que essa posição possa ser questionada, sua trajetória e história de vida o qualificam para ocupar esse lugar de fala.

Quando se insiste, neste artigo, na hipótese de uma única verdade que se desloca e circula nos dois textos, apesar dos aparentes conflitos neles contidos, é porque tanto na trajetória das casas-modelo como na trajetória de pai Euclides, é notável o lugar que os pesquisadores e seus respectivos estudos ocupam para definir relações e posições, que interferem tanto no campo religioso como no campo intelectual.

É possível interpretar o escrito de pai Euclides como detentor de um grande e precioso valor antropológico, pois sua trajetória como sacerdote e guardião da mina, que o levou também a publicar livros, defender e participar da construção de uma identidade africana em constante construção e transformação, está inserida num contexto político no qual está presente o saber antropológico. Do mesmo modo, é possível afirmar que os estudos antropológicos de Mundicarmo Ferretti expressam o tambor de mina e seus laços ancestrais com o Benin. Os textos de ambos, assim, foram forjados, escritos e construídos a partir da relação estabelecida no trabalho de campo, método por excelência da prática antropológica e etnográfica, por isso, é importante que sejam revisitados e questionados como saber antropológico e narrativa etnográfica. 


\section{CONSIDERAÇÕES FINAIS}

Os dois escritos analisados aqui, de pai Euclides da Casa Fanti Ashanti e da antropóloga Mundicarmo Rocha Ferretti, são de ricos e preciosos elementos teóricos e epistemológicos para compreender os movimentos, dinâmicas e relações que se estabelecem entre os campos religioso e intelectual ao acionarem conceitos, teorias, imagens, histórias e memórias. Em suma, ao acionarem saberes, conhecimentos e memórias que, antes de tudo, podem ser interpretados como resistência e força de uma não ontologia do ser presente na filosofia e ancestralidade africanas.

Os elos entre o tambor de mina e os rituais sagrados do Benin se construíram e se mantiveram através de canções entoadas aos voduns lá e cá por meio de símbolos, signos e também de agentes posicionados em diferentes campos que se relacionam a partir do trabalho de campo, o método antropológico. A busca em afirmar, construir e manter os vínculos entre os voduns do Maranhão e os voduns do Benin, assim, é algo inerente às inter-relações estabelecidas entre o campo intelectual e o campo religioso.

O trabalho de campo e a relação entre pesquisadora e pesquisado são acionados nos dois textos. Ambos reconhecem que seus achados, suas interpretações, suas posições e seus conhecimentos se cruzam no campo intelectual e no campo religioso. A dinâmica de mudanças, disputas e estratégias em jogo é reconhecida e vivida pelos agentes situados em campos relacionais, como o intelectual, da pesquisadora, e o religioso, do pesquisado, que, também pela trajetória, pode-se considerar um intelectual, atuando assim nos dois campos - publicou livros, dialoga com pesquisadores, acadêmicos, busca conhecimento sobre sua ancestralidade, aprende cantos africanos com um estudante africano e, principalmente, expõe essas estratégias, como é possível notar no seu artigo.

Respondendo à pesquisadora que mais tempo escreveu sobre sua casa, pai Euclides, de algum modo, calava uma certa crítica que se formava em torno da veracidade dos acontecimentos filmados e narrados no filme de pretensão etnográfica encenado por ele. Criticando o percurso de construção de uma identidade múltipla da casa que pesquisou por décadas, Mundicarmo Ferretti questiona o método do trabalho de campo. Como calar-se como antropóloga após o lançamento de um filme que enquanto tal não se baseia no mesmo rigor científico de suas pesquisas? Do mesmo modo, pai Euclides pôde questionar porque a narrativa acadêmica pode dizer quem sou e eu não? Ambos a partir dos escritos e trajetórias que construíram ocupam importantes posições nos seus respectivos campos, ambos questionaram a prática antropológica e a construção das relações estabelecidas no trabalho de campo decorrente dessa prática. 


\section{BIBLIOGRAFIA}

ABREU, Marilande M., 2009, Um Olhar sobre a Tradição: Relacionando Campo Religioso e Campo Intelectual. São Luís, MA: Edufma/Unicamp.

BArreto, Maria Amália Pereira, 1982, A Casa de Fanti Ashanti: Um Grupo Étnico?. São Paulo: UNESP.

BASTIDE, Roger, 1971, As Religiões Africanas no Brasil: Contribuição a Uma Sociologia das Interpenetrações de Civilizações (vol. II). São Paulo: Edusp.

BOURDIEU, Pierre, 1983, Questões de Sociologia. Rio de Janeiro: Marco Zero.

CAPONE, Stefania, 1999, La quête de l'Afrique dans le candomblé. Paris: Karthala.

DANTAS, Beatriz Góes, 1988, Vovó Nagô e Papai Branco: Usos e Abusos da África no Brasil. Rio de Janeiro: Edições Graal.

FERreIRA, Euclides Menezes, 2000, Bebeu da Minha Fonte e Sujou a Minha Água. São Luís, MA: mimeo.

FERretti, Mundicarmo R., 1991, Tambor de Mina, Cura e Baião na Casa Fanti Ashanti. São Luís, MA: SIOGE.

FERretTi, Mundicarmo R., 2000a, Desceu na Guma: o Caboclo não Tambor de Mina. São Luís, MA: Edufma.

FERretTI, Mundicarmo R., 2000b, Pureza Nagô e Nações Africanas no Tambor de Mina do Maranhão. São Luís, MA: mimeo.

FERRETTI, Mundicarmo R., 2001, "Pureza nagô e nações africanas no tambor de mina do Maranhão", Revista Ciência Sociais e Religião, 3 (3): 75-94.

FERRETTI, Sérgio, 1996, Querebentã de Zomadônu. São Luís, MA: Edufma.

PARÉS, Luis Nicolau, 1998-1999, "Atlântico negro: na rota dos Orixás - resenha", Revista Afro-Ásia, 21 -22: 367-375.

PEREIRA, Manuel Nunes, 1970, A Casa das Minas: Contribuição ao Estudo da Sobrevivência do Culto dos Voduns, do Panteão Daomeano no Estado do Maranhão. Petrópolis: Editora Vozes (2. ${ }^{\mathrm{a}}$ edição).

VERGER, Pierre, 1990, Uma Rainha Africana Mãe de Santo em São Luís. São Paulo: Edusp, 151-158.

WEBER, Max, 1999, "A objetividade do conhecimento nas ciências sociais", in Gabriel Cohn e Florestan Fernandes, Sociologia: Coleção Grandes Cientistas Sociais. São Paulo: Editora Ática, 79-127. 